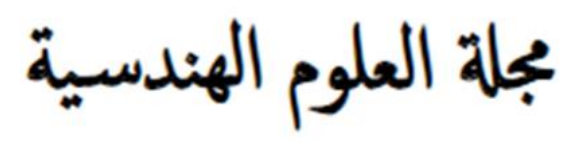

\title{
Shear Behavior in Beams Reinforced with Glass-Fiber Reinforced Polymer Bars (GFRPB) without stirrups
}

\author{
Osama Daoud $^{1, *}$ and Ahmed Fadul ${ }^{2}$ \\ 1 Building and Road Research Institute, Khartoum, Sudan \\ 2 Civil Engineering Department, University of Khartoum, Khartoum, Sudan \\ * Corresponding author: Osama Daoud (e-mail: eng.osama72@yahoo.com).
}

Article history: Received 14 March 2020, Received in revised form 4 November 2020, Accepted 11 November 2020

\begin{abstract}
The behavior and shear strength of concrete beams reinforced with glass fiber-reinforced polymer (GFRP) bars was investigated. Total of six reinforced concrete beams without stirrups were constructed and tested up to failure. The beams measured $1400 \mathrm{~mm}$ long, $150 \mathrm{~mm}$ wide and $300 \mathrm{~mm}$ deep and were tested in two-points bending with constant shear span $350 \mathrm{~mm}$ in all tested beams, and shear span to depth ratio a/d 1.37. The test variable was the reinforcement ratio. The test beams included three beams designed as tension control (T.C) with GFRP bars, three beams designed as compression control (C.C) with GFRP bars. The test results were compared with predictions provided by ACI 440.1R-15 design guideline and proposed equations in the literature. The test results indicated that the relatively low modulus of elasticity of FRP bars resulted in reducing shear strength. In addition, shear strength provided by ACI 440.1R-15 guideline underestimate shear strength capacity in which proposed equations in the literature had given better prediction than ACI 440.1R-15. The failure mode in T.C beams is diagonal tension by bond failure not by rupture of FRP and C.C beams is shear compression by crushing of the web in extreme fiber.
\end{abstract}

Keywords: GFRP-Fiber Reinforce Polymer, T.C-Tension Control, C.C-Compression Control, DT-Diagonal Tension, SC-Shear compression and S-steel.

\section{INTRODUCTION}

Corrosion has become one of the most prominent issues that encounter us in reinforced concrete structure, many solutions have been made to prevent it but none of them exhibit effective results until a few decades ago researchers have found a new material similar to conventional steel with high tensile strength which is called Fiber Reinforced Polymer (FRP).

Due to their durability, high strength-to-weight ratio, and good fatigue properties, fiber reinforced polymers (FRP) are considered an advantageous alternative to steel for internal reinforcement of concrete structures. However, the FRP reinforcement presents some differences when compared to steel reinforcing bars, such as a lower modulus of elasticity and a linear elastic stress-strain diagram up to rupture, which implies a lack of plastic behavior [1]. In addition, many steel-reinforced concrete structures exposed to deicing salts and marine environments require extensive and expensive maintenance. Recently, the use of fiber-reinforced polymer (FRP) as an alternative reinforcing material in reinforced concrete structures has emerged as an innovative solution to the corrosion problem [2].

The contribution of concrete $\mathrm{Vc}$ can be considered as a combination of five mechanisms activated after the formation of diagonal cracks Shear stresses in un-cracked compressed concrete, Aggregate interlock, Dowel action of the longitudinal reinforcing bars, Arch action and Residual tensile stresses transmitted directly 
across the cracks. All of these mechanisms provided by conventional steel RC elements are expected to be affected when using FRP reinforcement due to larger strains, the contribution of each shear component changes and depends on the load level and a crack pattern. In the beams without stirrups the problem to be investigated is the influence of a dowel effect on the shear capacity of FRP reinforced beams, particularly due to the FRP reinforcement in opposite to steel is an anisotropic material [1][2].

Aggregate interlock results from the resistance to relative slip between two rough interlocking surfaces of the crack, much like frictional resistance. As long as the crack is not too wide, this action can be significant. Dowel forces generated by longitudinal bars crossing the crack partially resist shearing displacements along the crack. Arching action occurs in deep members or in members in which the shear span-to-depth ratio $(\mathrm{a} / \mathrm{d})$ is less than 2.5 [3].

In the case of FRP reinforced beams without stirrups, cracks are more remarkable than in steel reinforced ones, since the modulus of elasticity of CFRP and GFRP bars are significantly lower than that of steel bars. Consequently, crack widths are bigger and the bars shear stiffness is lower, thus reducing both the aggregate interlock and the dowel action mechanisms [4].

Many researches focus in study the flexural behavior in beams reinforced with FRP, but researches in shear is not fully explored, in this paper experimental study to measure the effect of longitudinal reinforcement in beams reinforced with FRP in shear strength is presented.

The main aim of this paper is to get better conception on the behavior of beams reinforced with FRP without stirrups mainly:

Measure theoretical shear capacity using ACI 440.1R-15 and Equations in literature, then compare them with experimental shear capacity. In this paper some structural behaviors in serviceability limit state will be measured such as deflection of the beam, crack pattern and modes of failure.

\section{Literature review:}

Numbers of nine beams were tested, they reinforced with three types of bars GFRP, CFRP and conventional steel. The experimental results compared with predictions obtained by the equations from the guidelines, the test result indicates reduction in shear strength of FRP compared with steel due to the lower modulus of elasticity In addition, design method provided very conservative predictions, especially for beams reinforced with glass FRP bars[3].

The paper investigated the effect of modulus of elasticity of longitudinal reinforcing bars on the shear strength of slender reinforced concrete beams without transverse reinforcement and concluded that the shear strength is a function of the axial rigidity of longitudinal reinforcement[5].

The paper studied the shear capacities of concrete beams and compared with predictions calculated by guidelines ACI 440 and proposed equations and the found that guidelines underestimate the shear capacity of beams without stirrups [6].

\section{MATERIAL AND METHODS}

\section{Reinforcement:}

Glass FRP were used in this study as shown in Figure 1 with diameter $10 \mathrm{~mm}$, the characteristics of the glass FRP used in this study are summarized in Table 1.

TABLE I: MECHANICAL PROPERTIES OF FRP

\begin{tabular}{c|c|c}
\hline \hline PROPERTY & UNIT & GFRP \\
\hline DIAMETER & MM & 10 \\
\hline NOMINAL AREA $\left(\boldsymbol{A}_{\boldsymbol{f}, \boldsymbol{b a r}}\right)$ & MM2 & 78.5 \\
\hline ULTIMATE TENSILE STRENGTH & MPA & 938.4 \\
(GUARANTEED) $\left(\boldsymbol{f}_{\boldsymbol{f} \boldsymbol{u}}{ }^{*}\right)$ & & \\
\hline MODULUS OF ELASTICITY & GPA & 54 \\
(GUARANTEED) $\left(\boldsymbol{E}_{\boldsymbol{f}}\right)$ & & \\
\hline \hline
\end{tabular}

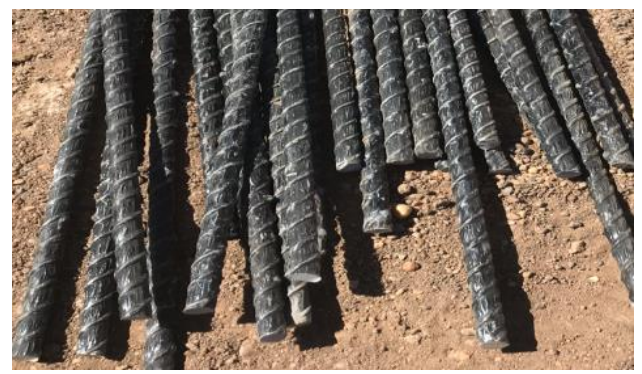

Fig. 1. Glass Fiber Reinforce Polymer.

Concrete:

The beams were constructed using normal weight concrete with a target compressive strength of $30 \mathrm{MPa}$ after 28 days. The mixture proportion per cubic meter of concrete was as follows: coarse aggregate content of $1146.35 \mathrm{~kg}$ 
with maximum size $20 \mathrm{~mm}$, fine aggregate content of $806.55 \mathrm{~kg}$, cement content of $324.85 \mathrm{~kg}$, water-cement ratio $(\mathrm{w} / \mathrm{c})$ of 0.49 , the mix were designed according to DOE in which ${f^{\prime}}_{c}$ is equal to $0.8^{f}$. The mix design properties are presented in Appendix B.

Where

$$
\begin{gathered}
f^{\prime}{ }_{c}=\text { Cylindrical strength } . \\
f_{c u}=\text { Compressive strength } .
\end{gathered}
$$

The seven beams were cast with the same mix having a specified (characteristics) compressive strength $\left(f_{c}^{\prime}\right)$ of $24 \mathrm{MPa}$. Experimental compressive strength was measured using three concrete cubes $\left(150^{*} 150^{*} 150 \mathrm{~mm}\right)$. The average compressive strength of cubes at 28 days was found to be $27.013 \mathrm{MPa}$.

\section{Casting, curing and storing:}

Concrete was mixed in the laboratory using standard method of mixing and cast in the same place. All specimens were placed and compacted using manual vibrators as shown in Figure $2 a-b$, the beams were covered with wet burlap on top of the burlap to prevent moisture loss can be seen in Figure 2c. The burlap was kept moist at all times during the curing period, which lasted 10 days. The formwork was stripped at the end of the second day, and the beams were stored in the laboratory until the day of testing.

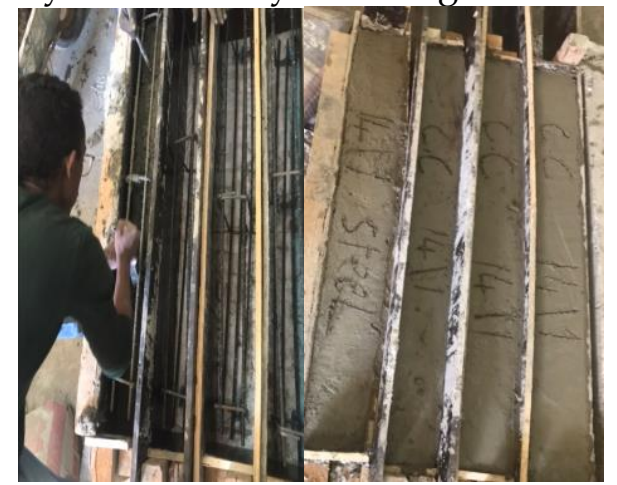

(a)

(b)

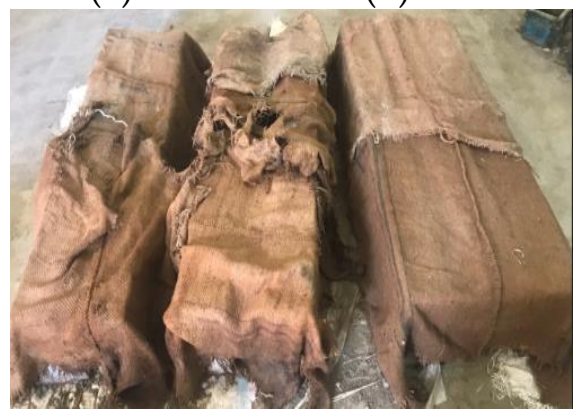

(c)

Fig. 2. Specimens (a) During compaction and casting, (b) After casting and (c) Curing of specimens.
Experimental Testing:

Experimental test was carried out and had been through multiple stages illustrated as follows:

\section{Specimens design:}

Seven reinforced concrete beams without transverse reinforcement were designed, constructed and tested up to failure. The tested beams were $1400 \mathrm{~mm}$ long, $150 \mathrm{~mm}$ wide, and 300 $\mathrm{mm}$ deep as shown in Figure 3. The test beams were divided into three categories with different reinforcement ratios. Each two categories included three beams reinforced with glass FRP, divided into tension control with $\mathrm{Q}=0.41 \%$ approximately $0.85 \mathrm{Qb}$ and compression control with @e $=0.621 \%$ approximately 1.6 .

\begin{tabular}{|c|c|c|c|c|c|}
\hline BEAM & $\begin{array}{l}\text { BEAM } \\
\text { WIDTH } \\
\text { (MM) }\end{array}$ & $\begin{array}{c}\text { BEAM } \\
\text { DEPTH } \\
(\mathrm{MM})\end{array}$ & $\begin{array}{c}\text { BOTTOM } \\
\text { REINFORCEMENT }\end{array}$ & $\begin{array}{c}\text { OP } \\
\text { REINFORCEMENT }\end{array}$ & $\boldsymbol{\rho}_{f} / \rho_{f b}$ \\
\hline $\begin{array}{l}\text { GFRP } \\
\text { T.C }\end{array}$ & \multirow{2}{*}{150} & \multirow{2}{*}{300} & $\begin{array}{c}2 \text { GFRP BARS } \\
\text { WITH DIAMETER } \\
10 \mathrm{MM}\end{array}$ & $\begin{array}{c}\text { 2GFRP BARS OF } \\
10 \mathrm{MM} \\
\text { DIAMETER }\end{array}$ & 0.85 \\
\hline $\begin{array}{l}\text { GFRP } \\
\text { C.C }\end{array}$ & & & $\begin{array}{c}3 \text { GFRP BARS } \\
\text { WITH DIAMETER } \\
10 \mathrm{MM}\end{array}$ & $\begin{array}{c}\text { 2GFRP BARS OF } \\
10 \mathrm{MM} \\
\text { DIAMETER }\end{array}$ & 1.6 \\
\hline
\end{tabular}

TABLE II: DETAILS OF TEST BEAMS.

The abbreviations T.C and C.C and refer to tension control and compression control respectively. The shear span was $350 \mathrm{~mm}$ for all tests and shear span to depth ratio $\mathrm{a} / \mathrm{d}=1.37$. Details of tested beams are listed in Table 2.

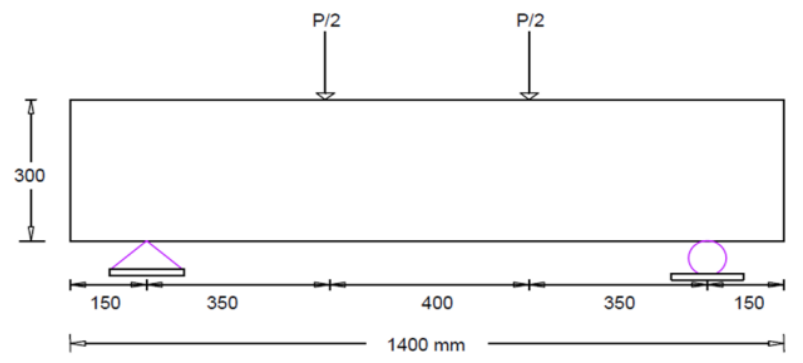

(a)
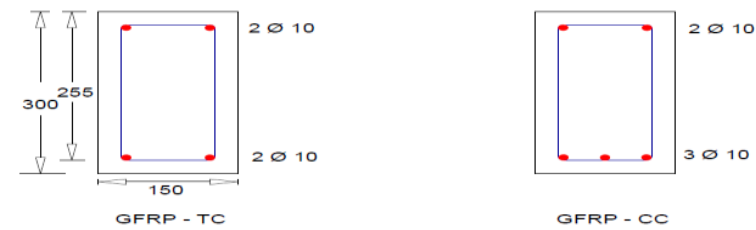

(b)

All dimension in $\mathrm{mm}$.

Clear cover $25 \mathrm{~mm}$.

Fig. 3. (a) Test setup and dimensions, (b) cross-sectional details.

Test setup and procedure:

The beams were tested at two-points concentrated load placed at the same distance 
from the support with shear span equal $350 \mathrm{~mm}$ using a hydraulic jack in Khartoum University over a simply supported clear span of $1100 \mathrm{~mm}$, as shown in Figure 4. During testing, load was applied gradually to measure deflection at mid span using dial gauge that placed at mid span. The loading was stopped when the first cracks appeared and the initial crack widths and deflection were measured, the applied load, displacements, and deflection were recorded during the test manually.

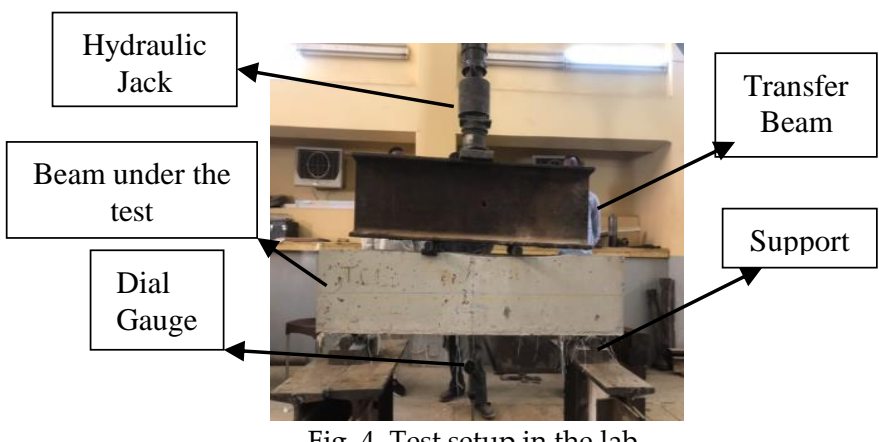

Fig. 4. Test setup in the lab.

\section{THEORY/CALCULATION}

Shear design of FRP according to ACI 440.1R-15 is similar to the steel reinforced concrete members but the different in mechanical properties affect the shear strength and should be considered.

The shear capacity provided by concrete according to ACI 440.1R-15 [7].

$$
\begin{aligned}
V_{c} & =\frac{2}{5} \sqrt{f^{\prime}}{ }_{c} b_{w}(k d) \\
\mathrm{k} & =\sqrt{2 \rho_{\mathrm{f}} \mathrm{n}_{\mathrm{f}}+\left(\rho_{\mathrm{f}} \mathrm{n}_{\mathrm{f}}\right)^{2}}-\rho_{\mathrm{f}} \mathrm{n}_{\mathrm{f}} \\
\mathrm{n}_{\mathrm{f}} & =\frac{\mathrm{E}_{\mathrm{f}}}{\mathrm{E}_{\mathrm{c}}} \\
E_{c} & =4700 \sqrt{f^{\prime}{ }_{c}}
\end{aligned}
$$

Shear capacity using proposed equation:

The concrete contribution to shear strength is calculated using the following equation:

I. El-Sayed et [3]

$$
\begin{aligned}
& \mathrm{V}_{\mathrm{c}, \mathrm{f}}=\left(\frac{\rho_{\mathrm{fE}_{\mathrm{f}}}}{90 \beta_{1} \mathrm{f}_{\mathrm{c}}^{\prime}}\right)^{1 / 3}\left(\frac{\sqrt{\mathrm{f}^{\prime}}}{6} \mathrm{~b}_{\mathrm{w}} \mathrm{d}\right) \\
& \text { II. Wegian et [6] } \\
& \quad \mathrm{V}_{\mathrm{c}}=2\left(\mathrm{f}^{\prime}{ }_{\mathrm{c}} \frac{\rho_{\mathrm{fE}_{\mathrm{f}}}}{\mathrm{E}_{\mathrm{s}}} \frac{\mathrm{d}}{\mathrm{a}}\right)^{1 / 3} \mathrm{~b}_{\mathrm{w}} \mathrm{d}
\end{aligned}
$$

\section{RESULTS AND DISCUSSION}

The test results which had been recorded during testing includes the shear at formation of initial crack, the experimental shear strength, the mode of failure, and mid span deflection are provided in Table 3.

Table 3: Summary of test result

\section{Structural behavior:}

The behavior of tested beams reinforced with FRP and steel can be illustrated as follows:

\section{Failure mode:}

The cracks were vertical cracks perpendicular to the direction of the maximum principal tensile stress induced by pure bending. As load increased, additional flexural cracks opened within the shear span Because of the dominance of the shear stresses, however, the cracks became progressively more inclined and propagated toward the load point as Shown in Figure 5, finally leading to diagonal tension failure in TC beams. This type of failure most likely to occur by reinforcement rupture, in this case the failure occurred by bond failure because bond in FRP is less than conventional steel as shown in Figure 6-a, the same behavior occurred in compression-controlled category but the main difference was the failure mode was compression failure controlled by the crushing of the concrete web as shown in Figure 6-b. The compression control FRP-reinforced beam reached the highest load, followed by tension reinforced beams beam reinforced with glass FRP bars.

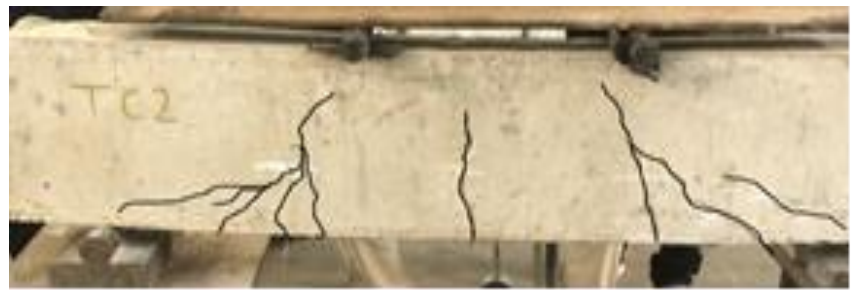

Fig. 5. Crack pattern in T.C beam.

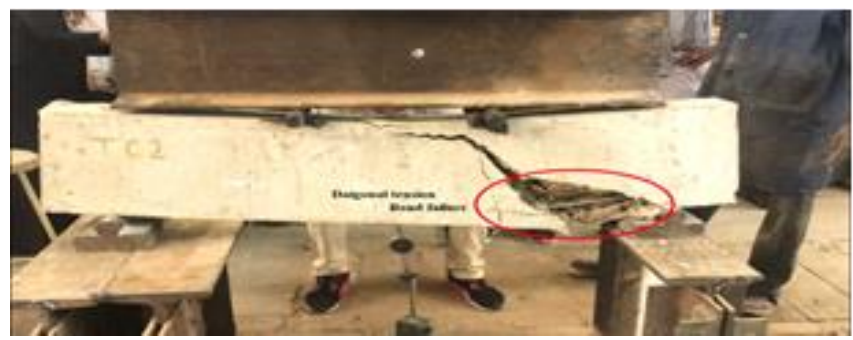

(a)

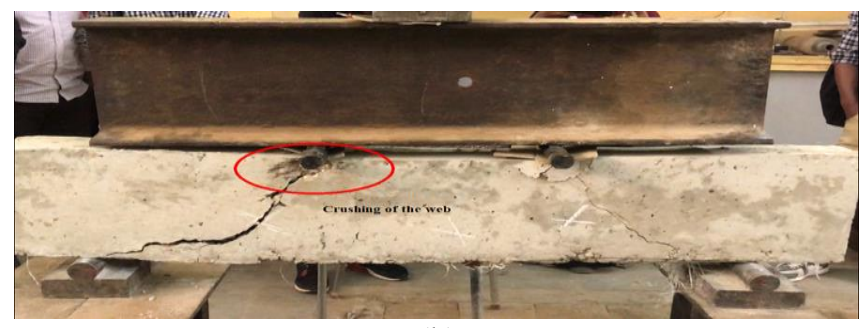

(b)

Fig. 6. Failure mode for (a) Tension control , (b) Compression control. 
Compression of prediction and experimental results:

The shear strengths of the tested beams reinforced with FRP bars were predicted using the shear design provisions of ACI $440.1 \mathrm{R}-15$ design guidelines and Equations in the literature. The predicted shear strengths were compared with the experimental values as given in Table-5, Equation 15 was used to predict the concrete shear strength of the tested FRP reinforced beams according to ACI 440.1R-15, It can be noticed from Table 4 that the ACI 440.1R-15 design method provides very conservative predictions, and underestimate shear strength this is an agreement with El-Sayed eto [3] this acceptable in design philosophy to increase factor of safety in applied load and reduction in shear strength. In this case the safety factor from calculating shear strength without any reduction in shear strength was about 6 times, but the amount of shear reinforcement that will be required more than what is needed and this as well uneconomic. Elsayed and many researchers had done several experimental tests to provide equation to determine shear strength capacity without shear reinforcement, as function in longitudinal reinforcement or function the ratio between modulus of elasticity of FRP to steel reinforcement. The proposed equations by had been used to predict shear strength capacity in which the equation provided by Elsayed gave factor of safety about 4.21, and the equation provided by Wegian gave factor of safety about 3.15 and these estimations clearly better than ACI 440.1R-15. It can be noticed that experimental shear strength is significantly higher than all predicted equations because shear span to depth ratio is less than two, and when increase span to depth ratio the flexural cracks forms in load relatively lower. Followed by diagonal cracks which will lead to shear failure in lower load.

TABLE III: SUMMARY OF TEST RESULT

\begin{tabular}{l|l|l|l|l|l}
\hline \hline Beam & $\begin{array}{l}\text { Initial } \\
\text { crack } \\
\text { KN }\end{array}$ & $\begin{array}{l}\text { Failure } \\
\text { load, } \\
\text { KN }\end{array}$ & $\begin{array}{l}\text { Experimental } \\
\text { shear } \\
\text { strength } \\
\text { Vexp kN }\end{array}$ & $\begin{array}{l}\text { Midspan } \\
\text { deflectio } \\
\text { n before } \\
\text { failure, } \\
\text { mm }\end{array}$ & $\begin{array}{l}\text { Failure } \\
\text { mode }\end{array}$ \\
\hline T.C-1 & 50 & 132 & 66 & 7.89 & DT \\
\hline T.C-2 & 40 & 135 & 67.5 & 11.41 & DT \\
\hline T.C-3 & 40 & 163 & 81.5 & 9.31 & DT \\
\hline C.C-1 & 50 & 150 & 75 & 6.47 & SC \\
\hline C.C-2 & 40 & 150 & 75 & 6.27 & SC \\
\hline C.C-3 & 55 & 100 & 50 & 4.87 & SC \\
\hline \hline
\end{tabular}

The theoretical shear capacities of the beams predicted according to the proposed Equations 18 and 19 and according to the ACI-440.1R-15 guidelines is shown in Figure 7.

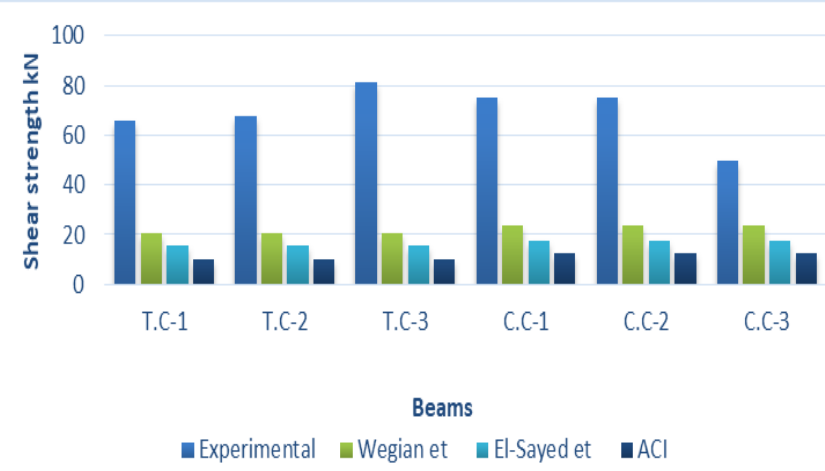

Fig. 7. Experimental and theoretical shear capacity of tested beams

\section{Deflection:}

The applied load versus mid-span deflection relationships of the tested beams are presented in Figure 8 . The typical load-deflection curve can be defined by two distinct stages. The first stage up to flexural cracking was similar for all beams representing the behavior of the un-cracked beam using the gross moment of inertia of the concrete cross section. The second stage, post-cracking up to failure, represents the cracked beam with reduced moment of inertia. The amount of longitudinal GFRP reinforcement had significant effect on the flexural stiffness in which beams reinforced as C.C beams exhibited deflection less than T.C beams because the amount of reinforcement in C.C beams is higher than T.C beams. In addition to that max deflection before failure was 9.5 and 6.37 for T.C and C.C respectively, and this less than permissible deflection for short term given by $(\mathrm{L} / 500=2.2$ $\mathrm{mm}$ ), and this most likely due to low modulus of elasticity.

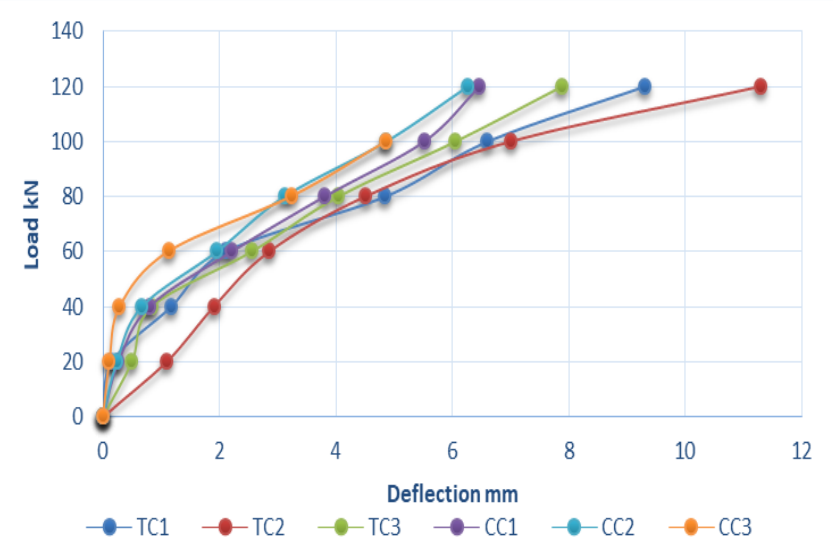

Fig. 8. Experimental Load-deflection behavior: all beams 
Table IV: Comparison of predicted and experimental shear capacities.

\begin{tabular}{|c|c|c|c|c|c|c|c|}
\hline \multirow{2}{*}{ Beam } & \multirow{2}{*}{$\begin{array}{c}\text { Experimental } \\
\text { shear } \\
\text { strength } \\
\mathrm{V}_{\exp } \mathrm{kN} \\
\end{array}$} & \multicolumn{2}{|c|}{ ACI $440.1 \mathrm{R}-15$} & \multicolumn{2}{|c|}{ Proposed Equation 18} & \multicolumn{2}{|c|}{ Proposed Equation 19} \\
\hline & & $\begin{array}{l}\text { Predicted } \\
\text { Shear } \\
\text { strength } \\
\mathrm{V}_{\text {pre, }} \mathrm{kN} \\
\end{array}$ & $V_{\exp } / V_{\text {pre }}$ & $V_{\text {pre }}$ & $V_{\exp } / V_{\text {pre }}$ & $V_{\text {pre }}$ & $V_{\text {exp }} / V_{\text {pre }}$ \\
\hline T.C-1 & 66 & 10.28 & 6.42 & 15.42 & 4.28 & 20.54 & 3.21 \\
\hline T.C-2 & 67.5 & 10.28 & 6.56 & 15.42 & 4.37 & 20.54 & 3.28 \\
\hline T.C-3 & 81.5 & 10.28 & 7.92 & 15.42 & 5.28 & 20.54 & 3.94 \\
\hline C.C-1 & 75 & 12.4 & 6.05 & 17.6 & 4.26 & 23.6 & 3.17 \\
\hline C.C-2 & 75 & 12.4 & 6.05 & 17.6 & 4.26 & 23.6 & 3.17 \\
\hline C.C-3 & 50 & 12.4 & 4.03 & 17.6 & 2.84 & 23.6 & 2.11 \\
\hline \multicolumn{2}{|c|}{ Mean } & & 6.17 & & 4.21 & & 3.15 \\
\hline \multicolumn{2}{|c|}{ Coefficient of variation, $\%$} & & 20.34 & & 18.55 & & 18.68 \\
\hline
\end{tabular}

\section{CONCLUSIONS}

The shear strength, dowel action and behavior of concrete slender beams reinforced with FRP bars has been investigated. Seven reinforced concrete beams without stirrups have been tested under two concentrated loads, three beams designed as tension control, three beams as compression beams and only one beam reinforced with conventional steel bars. The main findings of this investigation can be drawn as follows:

- The ACI 440.1R-15 guideline equations developed for concrete members reinforced with FRP significantly underestimate the shear capacity of the beams reinforced with FRP bars.

- Compared to the results of this study the shear strength has been estimated according to the proposed equations in literature give better results than the guideline. Giving factor of safety 4.21 and 3.15 times for Elsayed and wegian respectively, and the estimated shear strength is in a good agreement with the experimental results of this research.

- In the preliminary estimation for contribution of longitudinal reinforcement in terms of dowel action in beams reinforced with FRP is less than that carried by conventional steel due to low modulus of elasticity, especial instrument will be needed to measure shear displacement properly to get accurate results.
- Failure mode in T.C beams is diagonal tension by bond failure not by rupture of FRP, both C.C and Steel are shear compression by crushing of the web in extreme fiber.

- It's more preferable to design the beam as compression control because it gives warning that the section will collapse, but in tension control the failure after crack formations is sudden and catastrophic especially like what is occurred in the experiment the bond failure in tension zone.

- Beams reinforced with FRP show wider and deeper crack.

\section{REFERENCES}

[1] R. Fico, A. Prota, and G. Manfredi, "Assessment of Eurocode-like design equations for the shear capacity of FRP RC members," Compos. Eng., vol. 39, pp. 792-806, 2008.

[2] M. Kaszubska, R. Kotynia, and J. A. O. Barros, Influence of longitudinal GFRP reinforcement ratio on shear capacity of concrete beams without stirrups, vol. 193. The Author(s), 2017.

[3] A. K. El-sayed, E. F. El-salakawy, and B. Benmokrane, "Shear Strength of FRP-Reinforced Concrete Beams without Transverse Reinforcement," ACI Struct. J., vol. 235, no. 103, p. 10, 2006.

[4] A. Marí, A. Cladera, E. Oller, and J. Bairán, "Composites : Part B Shear design of FRP reinforced concrete beams without transverse reinforcement," Composites, vol. 57, pp. 228-241, 2014.

[5] M. S. Alam and A. Hussein, "Experimental investigation on the effect of longitudinal reinforcement on shear strength of fibre reinforced polymer reinforced concrete beams," Can. J. Civ. Eng., vol. 251, pp. 243-251, 2011.

[6] F. M. Wegian and H. A. Abdalla, "Shear capacity of concrete beams reinforced with fiber reinforced polymers," Compos. Struct., vol. 71, no. 1, pp. 130-138, 2005.

[7] A. C. I. Committee, ACI 440.1R-15: Guide for the Design and Construction of Structural Concrete Reinforced with FRP Bars. 
NOTATIONS:

$\mathrm{E}_{\mathrm{c}}=$ modulus of elasticity of concrete

$E_{f}=$ design or guaranteed modulus of elasticity of

FRP

$\mathrm{f}^{\prime}{ }_{\mathrm{c}}=$ specified compressive strength of concrete

$\mathrm{f}_{\mathrm{f}}=$ stress in FRP reinforcement in tension

$\mathrm{f}_{\mathrm{fu}}{ }^{*}=$ guaranteed tensile strength of FRP bar

$\mathrm{f}_{\mathrm{fu}}=$ design tensile strength of FRP

$\mathrm{V}_{\mathrm{c}}=$ nominal shear strength provided by concrete

$\rho_{\mathrm{f}}=$ FRP reinforcement ratio

$\rho_{\mathrm{fb}}=\mathrm{FRP}$ reinforcement ratio producing balanced strain conditions

$\mathrm{n}=$ ratio of modulus of elasticity of FRP bars to modulus of elasticity of concrete

$\mathrm{d}=$ distance from extreme compression fiber to centroid of tension reinforcement

$\mathrm{a}=$ shear span

$b_{w}=$ width of web 